\title{
Improving immunotherapy for colorectal cancer using dendritic cells combined with anti-programmed death-ligand in vitro
}

\author{
ZILONG HU ${ }^{1}$, YUE MA ${ }^{1}$, ZHIYANG SHANG ${ }^{2}$, SHIDONG HU $^{1}$, KAI LIANG ${ }^{1}$, \\ WENTAO LIANG $^{1}$, XIAOWEI XING ${ }^{1}$, YUFENG WANG ${ }^{3}$ and XIAOHUI DU ${ }^{1}$ \\ ${ }^{1}$ Department of General Surgery, Chinese People's Liberation Army General Hospital, Beijing 100853; \\ ${ }^{2}$ Department of Tumor Prevention and Rehabilitation, PKU Care Rehabilitation Hospital, Beijing 102206; \\ ${ }^{3}$ Department of Patient Admission Management, Chinese People's Liberation Army General Hospital, \\ Beijing 100853, P.R. China
}

Received November 26, 2016; Accepted November 29, 2017

DOI: $10.3892 / \mathrm{ol} .2018 .7978$

\begin{abstract}
Monoclonal antibodies recognizing programmed death-ligand 1 (PD-L1) have been used for the clinical treatment of diverse tumor types as a form of immune checkpoint inhibitor, with a favorable therapeutic effect. Dendritic cells (DCs) are potent antigen-presenting cells that serve a pivotal role in the activation of $\mathrm{T}$ cells, particularly cytotoxic $\mathrm{T}$ lymphocytes (CTLs). DC vaccines loaded with tumor antigens, DC-CTLs and activated T cells have been revealed to be a safe and effective treatment approach against colorectal cancer within a clinical setting. In addition to tumor cells, PD-L1 is also highly expressed on DCs. As research examining the association between anti-PD-L1 and DCs is lacking, the present study compared the expression of PD-L1 on DCs in the peripheral blood of healthy donors and patients with colorectal cancer. Following the application of anti-PD-L1, the DC phenotypes, function of DC-mediated T cell induction and the cytotoxicity of CTLs were investigated by flow cytometry. The present study revealed that treatment with anti-PD-L1 may promote the maturation of DCs and enhance the functionality of the $\mathrm{DC} 1$ subtype. It may also increase the number of CTLs that are activated and produce CTL cells with more potent anti-tumor activity. Therefore, the creation of DC vaccines in conjunction with anti-PD-L1 may be an effective future treatment strategy for patients with colorectal cancer.
\end{abstract}

\section{Introduction}

Colorectal cancer is the fourth leading cause of cancer-associated mortality worldwide (1). Immunotherapy has become

Correspondence to: Professor Xiaohui Du, Department of General Surgery, Chinese People's Liberation Army General Hospital, 28 Fuxing Road, Beijing 100853, P.R. China

E-mail: duxiaohui301@sina.com

Key words: immunotherapy, dendritic cells, anti-programmed death-ligand 1 , colorectal cancer a focus of research in association with colorectal cancer, and adoptive cell therapy (ACT) has been widely applied in a clinical setting as a treatment option $(2,3)$. Previous studies have suggested that ACT, which involves dendritic cell (DC) vaccines, cytotoxic T lymphocytes (CTLs), DC-CTLs and tumor infiltrating lymphocytes, and chimeric antigen receptor T-cell immunotherapy are safe and effective forms of immunotherapy in preclinical and clinical trials (3-5). However, the efficacy of these treatments remains subject to certain limitations due to tumor immune escape mechanisms, including the interaction between programmed cell death-1 (PD-1) and programmed death-ligand 1 (PD-L1) (6).

PD-L1 is a cell-surface protein that is selectively expressed in many tumor types (7). Through interacting with its corresponding receptor (PD-1 expressed on T cells), PD-L1 may suppress CTL-mediated responses against the tumor. As this suppression is detrimental to the anti-tumor response, blocking this interaction may help enhance cancer immunotherapy. In previous clinical trials, the therapeutic effect of inhibiting PD-1-mediated suppression has been improved by intravenously administering anti-PD-1 or anti-PD-L1 agents (8-12). However, immune checkpoint blockers may cause side effects, including the development of severe inflammation, which may become life threatening if not managed appropriately (13-15). Additional side effects may be caused by an upregulated immune response. Therefore, further research is required to identify an appropriate way of applying anti-PD-L1 agents within a clinical setting.

In addition to tumor cells, PD-L1 is also highly expressed on DCs (16-18). DCs are potent antigen-presenting cells and critical for the activation of T cells (19). Suppression of DC functions in patients with cancer is thought to contribute to the inhibition of the protective immune response and enhanced disease progression (20). At present, there are few studies that have compared the expression level of PD-L1 in DCs between healthy donors and patients with cancer. To the best of our knowledge, it is unknown whether PD-L1 expression on DCs that have been sensitized by tumor antigens will have an effect on $\mathrm{T}$ cell activation. Additionally, the effect of administering anti-PD-L1 to block the interaction between PD-1 and PD-L1 on DCs and activated T cells also remains unclear. Currently, 
the focus of the majority of ACT research is to enhance the anti-tumor effect of immune cells (21). In the present study, anti-PD-L1 was applied to cultures of DCs and during T cell activation to investigate whether it improved DC function and DC-mediated $\mathrm{T}$ cell activation.

\section{Materials and methods}

DC preparation and phenotype detection. Density gradient centrifugation was used for the preparation of peripheral blood mononuclear cells (PBMCs). Between May and July 2016, a volume of $20 \mathrm{ml}$ peripheral blood was obtained from 8 healthy donors and 11 patients with colorectal cancer in the Chinese PLA General Hospital (Beijing, China). There were 10 male patients and 9 female patients. The mean age of the patients was 53 years (range, 37-68 years). All participants in the present study provided written informed consent prior to their inclusion and the study was approved by the Ethics Committee of the Chinese PLA General Hospital. The samples were collected in a $50 \mathrm{ml}$ centrifuge tube containing heparin for anticoagulation. Following centrifugation of the samples at $1,600 \mathrm{x}$ for $30 \mathrm{~min}$ at $25^{\circ} \mathrm{C}$, the serum was removed using a pipette. A $50 \mathrm{ml}$ centrifuge tube was filled with normal saline (NS) and a $50 \mathrm{ml}$ centrifuge tube containing $20 \mathrm{ml}$ lymphocyte separation medium (Tianjin Haoyang Biological Products Technology Co., Ltd., Tianjin, China) was also prepared. The blood was mixed with the NS using a pipette and added to the surface of the lymphocyte separation medium along the tube wall. Following centrifugation of the samples at $1,000 \mathrm{x}$ for $30 \mathrm{~min}$ at $25^{\circ} \mathrm{C}$, the supernatant was removed. The PBMCs were collected from the corresponding layer and placed into another $50 \mathrm{ml}$ centrifuge tube. Following centrifugation of the sample at $500 \mathrm{xg}$ for $10 \mathrm{~min}$ at $25^{\circ} \mathrm{C}$, the serum was removed and normal saline (NS) was added. Following centrifugation again at $500 \mathrm{x} \mathrm{g}$ for $10 \mathrm{~min}$ at $25^{\circ} \mathrm{C}$, the serum was removed and the PBMCs were obtained. A $1 \mathrm{ml}$ volume of serum-free Cellix901 medium (Tianjin Haoyang Biological Products Technology Co., Ltd.) was added to the PBMCs and they were incubated for $3 \mathrm{~h}$ at $37^{\circ} \mathrm{C}$ in $5 \% \mathrm{CO}_{2}$. The cell suspension was removed and the adherent cells were scraped off the tube wall. The immature DCs (iDCs) from the peripheral blood were subsequently obtained. A total of $1,000 \mathrm{U} / \mathrm{ml}$ granulocyte-macrophage colony stimulating factor (GM-CSF) and interleukin (IL)-4 were added and the PBMCs were incubated at $37^{\circ} \mathrm{C}$ in $5 \% \mathrm{CO}_{2}$. GM-CSF and IL-4 were added daily to maintain a concentration of $1,000 \mathrm{U} / \mathrm{ml}$. Following 8 days of culture the mature DCs (mDCs) were harvested. The surface markers of the iDCs and mDCs were analyzed using flow cytometry (according to the method in the subsequent flow cytometry paragraph).

Applying anti-PD-L1 and the detection of DC phenotypes and cytokine production. The DCs were cultured as described above. On day 6, $5 \mu \mathrm{g} / \mathrm{ml}$ anti-PD-L1 monoclonal antibodies (cat. no. MPDL3280A; Genentech, San Francisco, CA, USA) were added to the test group and the same amount of NS was added to the control group. The DCs were harvested on day 8 , and a flow cytometry was performed to detect the expression of markers on DCs. Cytokines [IL-10, IL-12, tumor necrosis factor (TNF)- $\alpha$ and interferon (IFN)- $\gamma$ ] in the supernatants were detected using a cytometric bead array (CBA) (22).

CTL preparation and phenotype detection. The DCs were cultured and anti-PD-L1 was applied according to the aforementioned protocol. Isolated PBMCs were obtained and added to the mDCs in Serum-free Celix601 medium. The cells were incubated at $37^{\circ} \mathrm{C}$ in $5 \% \mathrm{CO}_{2}$. The following day, $1,000 \mathrm{U} / \mathrm{ml}$ anti-CD3 and $1,000 \mathrm{U} / \mathrm{ml} \mathrm{IL}-2$ were added to the cells. Following 3 days of culture at $37^{\circ} \mathrm{C}, 1,000 \mathrm{U} / \mathrm{ml} \mathrm{IL-2}$ was added every day and the CTLs were harvested following 14 days of culture. The expression of extracellular markers was measured using flow cytometry (according to the method in the subsequent flow cytometry paragraph).

Cytotoxicity of CTLs. A lactate dehydrogenase (LDH) release assay (CytoTox 96 ${ }^{\circledR}$ Non-Radioactive Cytotoxicity assay; Promega Corporation, Madison, WI, USA) was performed to test the cytotoxicity of the harvested CTLs in vitro. On day 14 of culture, the CTLs were resuspended to maintain a concentration of $1 \times 10^{6}$ cells $/ \mathrm{ml}$. The colorectal cancer cell line SW620 was purchased from the American Tissue Culture Collection (Manassas, VA, USA). It was collected during the logarithmic phase for use as the target cells. At 5:1 and 10:1 effector-target ratios, the CTL cytotoxicity was examined using an LDH release assay. The following formula was used to calculate cytotoxicity: Cytotoxicity=[A(Experimental)-A(Effector Spontaneous)-A(Target Spontaneous)x100/[A(Target maximum)-A(Target spontaneous)] (23).

Flow cytometry. The blocking reagent: $5 \%$ bovine serum albumin (BSA; Tianjin Haoyang Biological Products Technology Co., Ltd.) was added to the tube with a total of $1 \times 10^{5}$ cells in suspension for $15 \mathrm{~min}$ at $25^{\circ} \mathrm{C}$. After blocking, the cells were washed with the washing reagent $(0.5 \mathrm{ml} \mathrm{PBS})$. Then, the corresponding antibodies were added to a test tube for $15 \mathrm{~min}$ at $25^{\circ} \mathrm{C}$. And $2 \mathrm{ml}$ PBS with $5 \% \mathrm{BSA}$ was added. Following centrifugation at $400 \mathrm{x}$ g for $5 \mathrm{~min}$ at $25^{\circ} \mathrm{C}$, supernatant was removed. Then, $0.5 \mathrm{ml} \mathrm{PBS}$ was added to the tube and all samples were examined using a FACSCalibur instrument (BD Biosciences, San Jose, CA, USA), and the data were analyzed using FlowJo 7.6.1 software (FlowJo LLC, Ashland, OR, USA). The phenotypic profiles of iDCs and mDCs were analyzed via staining $1 \times 10^{5}$ cells for $15 \mathrm{~min}$ at $25^{\circ} \mathrm{C}$ with: Fluorescein isothiocyanate (FITC)-conjugated anti-CD86 (cat no. 555657), phycoerythrin (PE)-conjugated anti-CD80 (cat no. 340294), PE-PerCP-conjugated anti-HLA-DR (cat no. 347364), allophycocyanin (APC)-conjugated anti-CD83 (cat no. 551073), PE-conjugated anti-PD-L1 (cat no. 557924) and PE-conjugated anti-CD11c (cat no. 340544), APC-conjugated anti-CD123 (cat no. 340545). The phenotypic profiles of CTLs, helper T cells, and NK cells were analyzed via staining $1 \times 10^{5}$ cells for $15 \mathrm{~min}$ at $25^{\circ} \mathrm{C}$ with: FITC-conjugated anti-CD4 (cat no. 340298), PE-conjugated anti-CD8 (cat no. 340298), PE-PerCP-conjugated anti-CD3 (cat no. 340298), and APC-conjugated anti-CD56 (cat no. 341025). The phenotypic profiles of Tregs were analyzed via staining $1 \times 10^{5}$ cells for $15 \mathrm{~min}$ at $25^{\circ} \mathrm{C}$ with: FITC-conjugated anti-CD4 (cat no. 340133), PE-conjugated anti-CD127 (cat no. 557938), PE-PerCP-conjugated anti-CD3 (cat no. 347344) and 

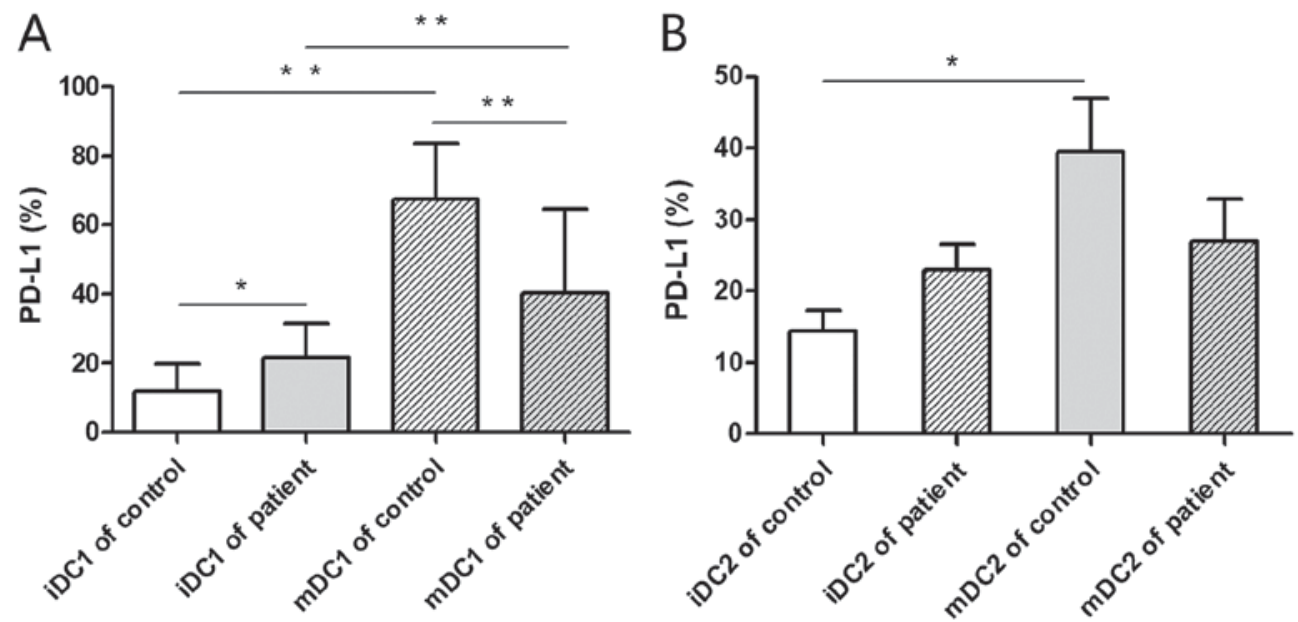

Figure 1. PD-L1 expression on iDCs and mDCs. iDCs from the peripheral blood of healthy donors and patients with colorectal cancer were obtained. The phenotype of the iDCs was analyzed by flow cytometry. Monocytes isolated from peripheral blood mononuclear cells underwent maturation for 8 days and mDCs were then harvested. The phenotypes of the mDCs were analyzed by flow cytometry. The PD-L1 expression rates on (A) DC1 and (B) DC2 cells were analyzed. ${ }^{*} \mathrm{P}<0.05$ and ${ }^{* *} \mathrm{P}<0.01$. iDC, immature dendritic cell; $\mathrm{mDC}$, mature dendritic cell; PD-L1, programmed death-ligand 1.

APC-conjugated anti-CD25 (cat no. 340939). All the antibodies were purchased from BD Biosciences and employed according to the manufacturer's protocols.

Statistical analysis. Data are expressed as the mean \pm standard deviation from at least three independent experiments. Statistical analyses, including a Chi-square test, Student's t-tests and a Fisher's exact test were performed as appropriate. One-way analysis of variance and a Newman-Keuls post hoc test were used to compare differences among multiple groups. For all tests, $\mathrm{P}<0.05$ was considered to indicate a statistically significant difference. SPSS version 23.0 (IBM Corp., Armonk, NY, USA) and GraphPad Prism 5.0 (GraphPad Software, Inc., La Jolla, CA, USA) was used for data analysis.

\section{Results}

$P D$-L1 expression on DCs. Flow cytometry was performed for the detection of PD-L1 expression on DC1 and DC2 subsets. The PD-L1 expression rate on $\mathrm{mDC} 1$ cells was significantly higher compared with iDC1s in healthy donors and patients with colorectal cancer $(\mathrm{P}<0.01$; Fig. 1A). This indicates that PD-L1 expression is upregulated during the formation and maturation of DC1s. The PD-L1 expression rate on iDC1s was significantly higher from the peripheral blood of patients with colorectal cancer compared with healthy donors $(\mathrm{P}<0.05$; Fig. 1A). This indicates that PD-L1 expression on iDC1 subsets may be significantly upregulated within the tumor microenvironment. Additionally, the PD-L1 expression rate of mDC2s was significantly higher compared with iDC2s in healthy donors $(\mathrm{P}<0.05)$ while no significant difference was observed in those derived from the patients with colorectal cancer (Fig. 1B).

DC phenotype detection. Mature DC cell surface markers were detected by flow cytometry (Fig. 2). In the anti-PD-L1 group DC surface markers, including CD80, CD83 and CD86 were expressed at a frequency of $97.03 \pm 2.87,84.80 \pm 5.12$ and

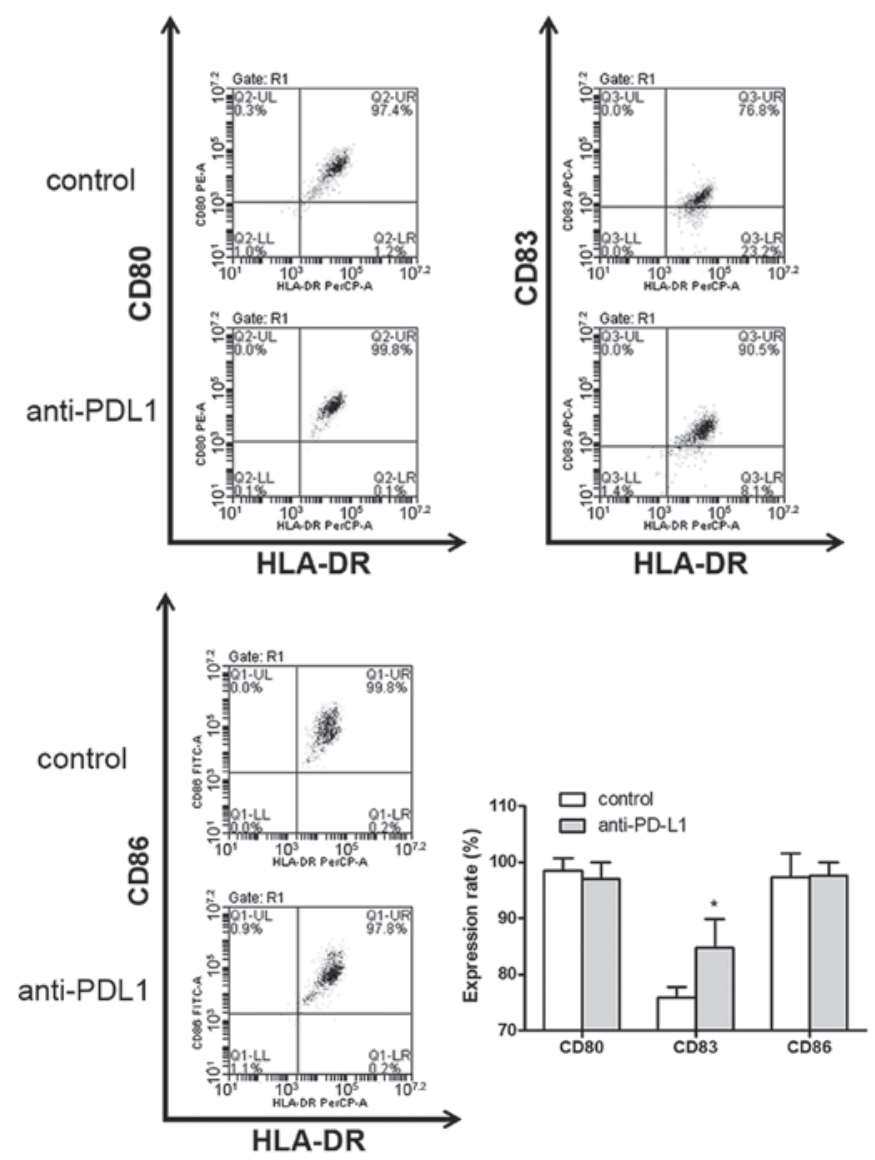

Figure 2. Anti-PD-L1 promotes DC maturation and proliferation in vitro. Following 8 days in culture mDCs were harvested. A blockade of the programmed cell death-1/PD-L1 interaction was performed on day 6. $\mathrm{mDC}$ cell surface markers were detected by flow cytometry. The surface expression rates of CD80,CD83 and CD86 on mDCs were compared. "P $<0.05$ vs. control. $\mathrm{mDC}$, mature dendritic cells; CD, cluster of differentiation; PD-L1, programmed death-ligand 1; HLA-DR, human leukocyte antigen-antigen D related.

$97.57 \pm 2.46 \%$, respectively (data not shown). In the control group, the percentage of CD80, CD83 and CD86 detected was $98.60 \pm 2.08,75.83 \pm 1.94$ and $97.30 \pm 4.33 \%$, respectively 

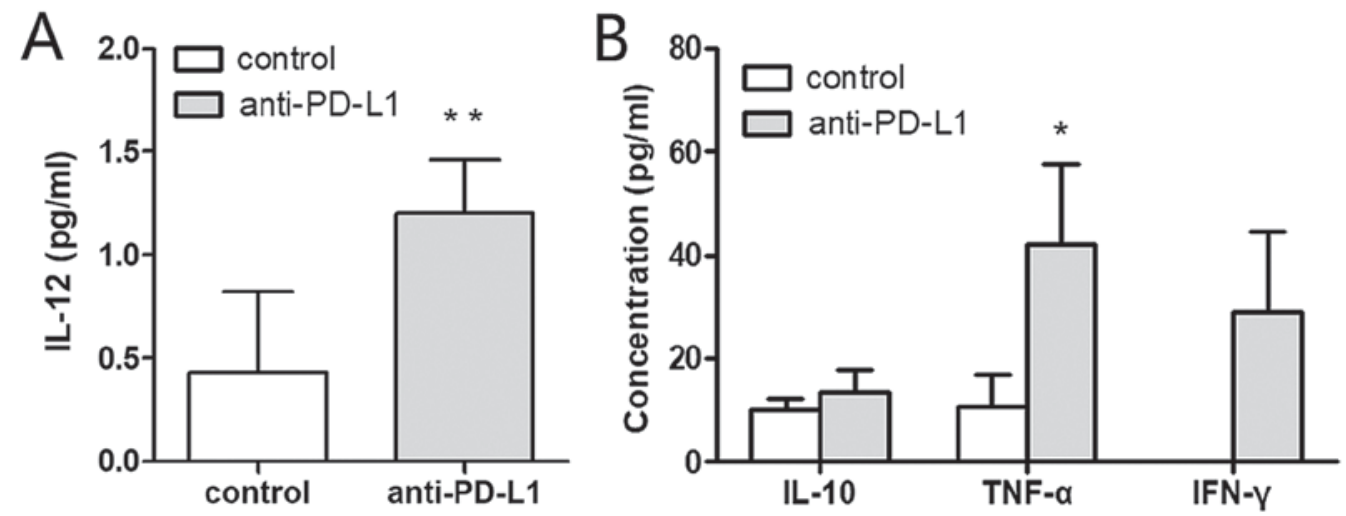

Figure 3. Anti-PD-L1 induces mDCs with increased secretion of effector cytokines. Cytometric bead array was used to evaluate cytokine concentrations in the dendritic cell culture supernatants on day 7. (A) The concentration of IL-12 in the control and anti-PD-L1 groups was analyzed. (B) IL-10, TNF- $\alpha$ and IFN- $\gamma$ concentrations in the supernatants were detected and compared between the two groups. The IFN- $\gamma$ concentration was undetectable in the control group. ${ }^{*} \mathrm{P}<0.05$ and ${ }^{* *} \mathrm{P}<0.01$ vs. control. IL, interleukin; PD-L1, programmed death-ligand 1; TNF, tumor necrosis factor; IFN, interferon.

(data not shown). CD83 expression on DCs in the anti-PD-L1 group was significantly higher compared with the control group ( $\mathrm{P}<0.05$; Fig. 2). There was no statistically significant difference observed between the two groups regarding the expression of CD80 and CD86 on DCs.

Cytokine assays. Cytokines within the supernatants were measured by CBA. The IL-12 concentration was significantly higher in the anti-PD-L1 group compared with the control group, $1.20 \pm 0.26$ and $0.43 \pm 0.39 \mathrm{pg} / \mathrm{ml}$, respectively ( $\mathrm{P}<0.01$; Fig. 3A). The level of TNF- $\alpha$ was also significantly increased in the anti-PD-L1 group compared with the control, $42.12 \pm 15.47$ and $10.67 \pm 6.38 \mathrm{pg} / \mathrm{ml}$, respectively $(\mathrm{P}<0.05$; Fig. 3B). The IFN- $\gamma$ concentration in the anti-PD-L1 group was $28.87 \pm 15.57 \mathrm{pg} / \mathrm{ml}$, but it was undetectable in the control group. IFN- $\gamma$ was significantly higher in the anti-PD-L1 group, compared with the control $(\mathrm{P}<0.05)$. The concentration of IL-10 in the anti-PD-L1 and control groups was $13.52 \pm 4.19$ and $9.92 \pm 2.47 \mathrm{pg} / \mathrm{ml}$, respectively $(\mathrm{P}<0.05)$. However, no statistically significant differences were observed regarding the concentration of IL-10 secreted in each group.

CTL phenotype detection. The CTL phenotype was measured by flow cytometry and compared between the two groups (Fig. 4A and B). In the anti-PD-L1 group, the percentage of helper $\mathrm{T}$ cells $\left(\mathrm{CD}^{+} \mathrm{CD}^{+}\right)$, cytotoxic $\mathrm{T}$ lymphocytes $\left(\mathrm{CD}^{+} \mathrm{CD}^{+}\right)$, NK cells $\left(\mathrm{CD}^{-} \mathrm{CD}^{-} 6^{+}\right)$and regulatory $\mathrm{T}$ cells $\left(\mathrm{CD} 3{ }^{+} \mathrm{CD} 4^{+} \mathrm{CD} 25^{+} \mathrm{CD} 127^{-}\right)$in the $\mathrm{CTL}$ cultures was $3.53 \pm 1.71$, $79.57 \pm 2.81,7.87 \pm 0.45$ and $1.73 \pm 0.46 \%$, respectively. In the control group the percentages were $14.97 \pm 9.07,58.17 \pm 4.21$, $8.13 \pm 0.84$ and $2.37 \pm 1.46 \%$, respectively. These results indicated that there was a significantly higher percentage of cytotoxic $\mathrm{T}$ lymphocytes $\left(\mathrm{CD}^{+} \mathrm{CD}^{+}\right)$in the anti-PD-L1 group compared with the control group $(\mathrm{P}<0.05$; Fig. $4 \mathrm{C})$. The percentage of helper $\mathrm{T}$ cells $\left(\mathrm{CD}^{+} \mathrm{CD}^{+}\right.$; Fig. $\left.4 \mathrm{C}\right)$ was notably lower in the anti-PD-L1 group compared with the control, however there were no significant differences, in comparison of $\mathrm{NK}$ cells (CD3-CD56 ${ }^{+}$; Fig. 4D) and regulatory $\mathrm{T}$ cells $\left(\mathrm{CD} 3^{+} \mathrm{CD} 4^{+} \mathrm{CD} 25^{+} \mathrm{CD} 127^{-}\right.$; Fig. 4D) between the two groups.
Cytotoxicity of CTLs. To confirm the anti-tumor effects of CTLs induced by DCs treated with monoclonal antibodies against PD-L1, their cytotoxicity was examined by an LDH release assay. In an in vitro killing experiment at the 5:1 effector-target ratio, the cytotoxicity in the anti-PD-L1 and control groups was $25.21 \pm 5.02$ and $7.68 \pm 1.86 \%$, respectively $(\mathrm{P}=0.005$; Fig. 5). When the same experiment was performed at the 10:1 effector-target ratio, the cytotoxicity in the anti-PD-L1 and control groups was $56.88 \pm 1.82$ and $44.96 \pm 5.23 \%(\mathrm{P}=0.02$; Fig. 5). The CTLs induced by DCs combined with anti-PD-L1 demonstrated a significantly higher cytotoxicity towards the human colorectal cancer cell line SW620 in vitro compared with the CTLs without anti-PD-L1 in the control group at each effector-target ratio. These results indicate that PD-L1 expression on DCs restrains the DC function and decreases CTL proliferation. Additionally, blocking the PD-1/PD-L1 interaction may rescue this impairment and improve the anti-tumor effect of CTLs.

\section{Discussion}

PD-L1 is highly expressed on DCs and is one of the immune checkpoints of the human immune system (24). The binding of PD-1 on the surface of various immune cells, including T cells, induces an inhibitory effect and regulates the immunological function of the human body (25). Curiel et al (26) demonstrated that the expression rate of PD-L1 on DCs may be significantly upregulated within the tumor microenvironment. DCs have the ability to present antigens, as well as suppress the immune response mediated by the interaction of PD-L1 and PD-1 (25). Blocking the PD-1/PD-L1 interaction may benefit certain patients with cancer (10). However, it is unclear whether using anti-PD-L1 combined with ACT will produce better curative effects. Therefore, it is essential to improve the curative effect, minimize side effects and seek an appropriate approach to using anti-PD-L1 in the treatment of cancer within a clinical setting.

DC subsets primarily consist of DC1 (HLA-DR ${ }^{+}, \mathrm{CD}_{11 \mathrm{c}^{+}}$ and $\mathrm{CD}^{-23^{-}}$) and $\mathrm{DC} 2$ subsets (HLA-DR ${ }^{+}, \mathrm{CD}^{2} 1 \mathrm{c}^{-}$and $\mathrm{CD}_{123^{+}}$) (27). The DC1 subset serves a key role in anti-tumor cytotoxicity due to its robust antigen-presentation capacity and 

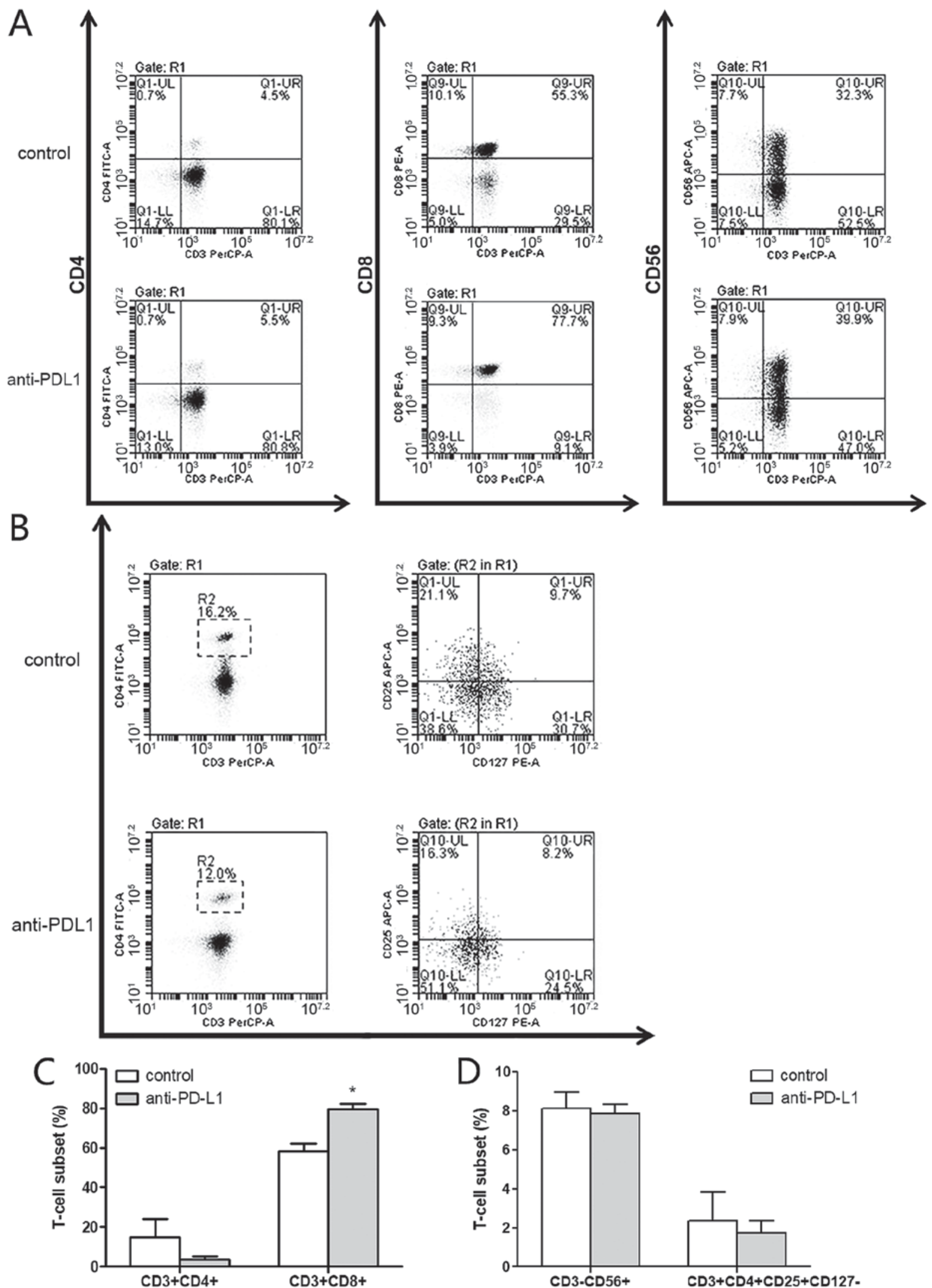

Figure 4. Anti-PD-L1 induces a higher percentage of CTLs in vitro. Expression of surface markers was measured on day 15 by flow cytometry analysis. (A and B) Antibodies directed against CD3, CD4, CD8, CD56, CD25 and CD127 were used to measure the expression of cell surface markers by flow cytometry. (C) The percentage of helper $\mathrm{T}$ cells $\left(\mathrm{CD}^{+} \mathrm{CD} 4^{+}\right)$and cytotoxic $\mathrm{T}$ lymphocytes $\left(\mathrm{CD} 3^{+} \mathrm{CD} 8^{+}\right)$. (D) The percentage of $\mathrm{NK}^{-}$cells $\left(\mathrm{CD}^{-} \mathrm{CD} 56^{+}\right)$and regulatory $\mathrm{T}$ cells $\left(\mathrm{CD}^{+} \mathrm{CD}^{+} \mathrm{CD} 25^{+} \mathrm{CD} 127\right)$. " $\mathrm{P}<0.05$ vs. control. $\mathrm{CD}$, cluster of differentiation; NK, natural killer; PD-L1, programmed death-ligand 1.

T cell activating abilities (28). In the present study, the PD-L1 expression rate on $\mathrm{mDC} 1 \mathrm{~s}$ was higher than that expressed on
iDC1s in healthy donors and patients with colorectal cancer. This indicates that the PD-L1 expression rate on the DC1 


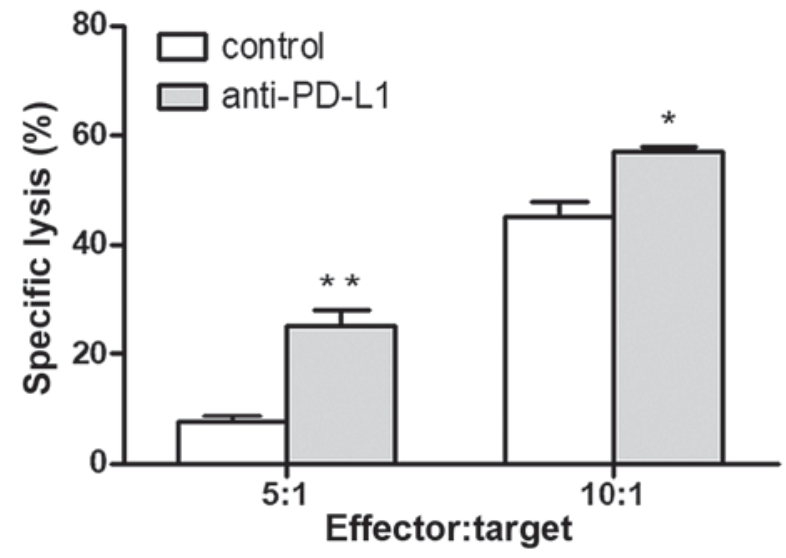

Figure 5. Anti-PD-L1 induces an enhanced anti-tumor cytotoxicity against the human colorectal cancer cell line SW620 in vitro. The cytotoxicity of CTLs was determined in vitro at 5:1 and 10:1 effector-target ratios against SW620 cells. ${ }^{*} \mathrm{P}<0.05$ and ${ }^{* *} \mathrm{P}<0.01$ vs. control. CTL, cytotoxic T lymphocytes; PD-L1, programmed death-ligand 1.

subset increases with DC maturation. Since the high expression of PD-L1 in DC1 subsets will have negative effects on immune response, applying anti-PD-L1 during the activation and differentiation of $\mathrm{T}$ cells may reduce the negative suppressive effects of the DC1 subsets. Additionally, the PD-L1 expression rate of iDC1s in patients with colorectal cancer was higher than that of healthy donors, and the patients with colorectal cancer exhibited a lower PD-L1 expression rate on $\mathrm{mDC1}$ s compared with the healthy donors. These results indicate that there was no corresponding increase in PD-L1 expression associated with DC maturation in colorectal cancer patients. These findings may explain the poor functionality of DCs in patients undergoing ACT, however further study is required to confirm this suggestion.

DC cell-surface markers were also measured in the present study. The DC maturation marker, CD83, co-stimulatory molecules CD80 and CD86, and major histocompatibility complex (MHC) class II molecule, HLA-DR were compared between the PD-L1 and control groups. The expression level of these markers reflects the degree of maturity and functional status of the DCs (29). In the present study, no statistically significant differences were observed between the two groups for the comparison of CD80, CD86 and MHC. However, the CD83 expression rate in the anti-PD-L1 group was significantly higher compared with the control group. A high expression level of CD83 suggests that treatment with monoclonal antibodies against PD-L1 promotes DC maturation and enhances its associated functionality.

IL-12 produced by DCs, B cells and macrophages is one of the most potent type $1 \mathrm{~T}$ helper cytokines and may promote the activation of CTL and NK cells (30). IL-12 has also been used as a cytokine for improving DC-based immunotherapy (31). In the present study, cytokine detection by CBA revealed that the concentration of IL-12 was significantly higher in the anti-PD-L1 group. An increased secretion of IL-12 by DCs may translate into enhanced anti-tumor immunity (31). However, the concentration of IL-10, which may impair the potent APC function of DCs and produce negative effects on immunity (32), was not significantly different between the two groups in the present study. This suggests that there is no association between the administration of anti-PD-L1 and IL-10 secretion by DCs. TNF- $\alpha$ was reported to be able to induce the necrosis and apoptosis of tumor cells directly $(33,34)$. In the present study, following treatment with anti-PD-L1 the secretion of TNF- $\alpha$ was significantly increased compared with the control. According to previous adoptive T-cell transfer studies, IFN- $\gamma$ was reported to be crucial for efficient tumor rejection by the upregulation of MHC class I and Fas levels on tumor cells (35). In the present study it was revealed that only a small amount of IFN- $\gamma$ was secreted when anti-PD-L1 was added while the DCs were maturing, whereas IFN- $\gamma$ secretion in the control group was undetectable. As the increased secretion of TNF- $\alpha$ and IFN- $\gamma$ may enhance anti-tumor effects, applying anti-PD-L1 to maturing DCs may produce DC vaccines with a higher immune activating potential.

CTLs are regarded as ideal cells for immunotherapy, as they possess strong tumor specificity and exhibit stable antitumor effects in clinical trials (36). At present, the improvement of DC-mediated activation and proliferation of CTLs is a challenge for ACT. According to the results of the present study, applying anti-PD-L1 during the induction and activation of $\mathrm{T}$ cells may produce a higher percentage of CTLs $\left(\mathrm{CD}^{+}, \mathrm{CD}^{+}\right)$. One possible reason for this observation may be the improved function of the DC1 subset. As PD-L1 was highly expressed on the DC1 subset following the application of anti-PD-L1, the function of the DC1 subset was enhanced. Furthermore, as described above the DC1 subset was demonstrated to serve a leading role in antigen presentation and CTL induction. Therefore, the application of anti-PD-L1 may effectively increase the percentage of CTLs. As key players in driving immune suppression, regulatory $\mathrm{T}$ cells (Tregs) may inhibit anti-tumor immunity within the tumor microenvironment. In the present study, although the percentage of Tregs was lower in the anti-PD-L1 group, there was no significant difference between the two groups. Further studies are required to examine whether applying anti-PD-L1 is associated with a lower percentage of Tregs. Additionally, the CTL cytotoxicity against the human colorectal cancer cell line SW620 was examined in the present study using an LDH release assay. At 5:1 and 10:1 effector-target ratios the cytotoxicity of the anti-PD-L1 group was significantly higher compared with the control group. The authors hypothesize that the increase in CTLs was the primary reason for the improved cytotoxicity, however cytokine changes in IL-12, TNF- $\alpha$ and IFN- $\gamma$ may also contribute to the observed enhanced anti-tumor effect.

In summary, treatment with anti-PD-L1 may promote the maturation of DCs and enhance the functionality of the DC1 subtype. It may also improve the ability of CTL activation and produce CTL cells with more potent anti-tumor activity. As applying anti-PD-L1 may also enhance DC vaccines and DC-based immunotherapy, the creation of DC vaccines in conjunction with anti-PD-L1 may be a future effective treatment strategy for patients with colorectal cancer.

\section{Competing interests}

The authors declare that they have no competing interests. 


\section{References}

1. Brenner H, Kloor M and Pox CP: Colorectal cancer. Lancet 383 1490-1502, 2014

2. Makkouk A and Weiner GJ: Cancer immunotherapy and breaking immune tolerance: New approaches to an old challenge. Cancer Res 75: 5-10, 2015.

3. Chia WK, Teo M, Wang WW, Lee B, Ang SF, Tai WM, Chee CL, $\mathrm{Ng}$ J, Kan R, Lim WT, et al: Adoptive T-cell transfer and chemotherapy in the first-line treatment of metastatic and/or locally recurrent nasopharyngeal carcinoma. Mol Ther 22: 132-139, 2014.

4. Jin CG, Chen XQ, Li J, Wu ZP, Liu X and Wang XC: Moderating effects and maintenance of lung cancer cellular immune functions by CIK cell therapy. Asian Pac J Cancer Prev 14: 3587-3592, 2013.

5. Mesiano G, Todorovic M, Gammaitoni L, Leuci V, Giraudo Diego L, Carnevale-Schianca F, Fagioli F, Piacibello W, Aglietta M and Sangiolo D: Cytokine-induced killer (CIK) cells as feasible and effective adoptive immunotherapy for the treatment of solid tumors. Expert Opin Biol Ther 12: 673-684, 2012.

6. Kelly RJ: Immunotherapy for esophageal and gastric cancer. Am Soc Clin Oncol Educ Book 37: 292-300, 2017.

7. Zou WP and Chen LP: Inhibitory B7-family molecules in the tumour microenvironment. Nat Rev Immunol 8: 467-477, 2008.

8. Brahmer JR, Drake CG, Wollner I, Powderly JD, Picus J, Sharfman WH, Stankevich E, Pons A, Salay TM, McMiller TL, et al: Phase I study of single-agent anti-programmed death-1 (MDX-1106) in refractory solid tumors: Safety, clinical activity, pharmacodynamics, and immunologic correlates. J Clin Oncol 28: 3167-3175, 2010

9. Chung HC, Arkenau HT, Wyrwicz L, Oh DY, Lee KW, Infante JR, Chin KM, von Heydebreck A, Kang YK and Safran H: Safety, PD-L1 expression, and clinical activity of avelumab (MSB0010718C), an anti-PD-L1 antibody, in patients with advanced gastric or gastroesophageal junction cancer. J Clin Oncol 34 (4 suppl): S167, 2016.

10. Hamid O, Robert C, Daud A, Hodi FS, Hwu WJ, Kefford R Wolchok JD, Hersey P, Joseph RW, Weber JS, et al: Safety and tumor responses with lambrolizumab (anti-PD-1) in melanoma. N Engl J Med 369: 134-144, 2013

11. Topalian SL, Sznol M, McDermott DF, Kluger HM, Carvajal RD, Sharfman WH, Brahmer JR, Lawrence DP, Atkins MB Powderly JD, et al: Survival, durable tumor remission, and long-term safety in patients with advanced melanoma receiving nivolumab. J Clin Oncol 32: 1020-1030, 2014.

12. Wolchok JD, Kluger H, Callahan MK, Postow MA, Rizvi NA, Lesokhin AM, Segal NH, Ariyan CE, Gordon RA, Reed K, et al Nivolumab plus ipilimumab in advanced melanoma. N Engl J Med 369: 122-133, 2013.

13. Hofmann L, Forschner A, Loquai C, Goldinger SM, Zimmer L, Ugurel S, Schmidgen MI, Gutzmer R, Utikal JS, Göppner D, et al Cutaneous, gastrointestinal, hepatic, endocrine, and renal side-effects of anti-PD-1 therapy. Eur J Cancer 60: 190-209, 2016

14. Helissey C, Vicier C and Champiat S: The development of immunotherapy in older adults: New treatments, new toxicities? J Geriatr Oncol 7: 325-333, 2016

15. Cousin S and Italiano A: Molecular pathways: Immune checkpoint antibodies and their toxicities. Clin Cancer Res 22: 4550-4555, 2016

16. Selenko-Gebauer N, Majdic O, Szekeres A, Höfler G, Guthann E, Korthäuer U, Zlabinger G, Steinberger P, Pickl WF, Stockinger $\mathrm{H}$, et al: B7-H1 (programmed death-1 ligand) on dendritic cells is involved in the induction and maintenance of T cell anergy. J Immunol 170: 3637-3644, 2003.

17. Atefi M, Avramis E, Lassen A, Wong DJ, Robert L, Foulad D, Cerniglia M, Titz B, Chodon T, Graeber TG, et al: Effects of MAPK and PI3K pathways on PD-L1 expression in melanoma. Clin Cancer Res 20: 3446-3457, 2014

18. Okazaki T and Honjo T: PD-1 and PD-1 ligands: From discovery to clinical application. Int Immunol 19: 813-824, 2007.
19. Palucka $\mathrm{K}$ and Banchereau J: Cancer immunotherapy via dendritic cells. Nat Rev Cancer 12: 265-277, 2012.

20. Hargadon KM: Strategies to improve the efficacy of dendritic cell-based immunotherapy for melanoma. Front Immunol 8: 1594, 2017

21. Tähtinen S, Grönberg-Vähä-Koskela S, Lumen D, Merisalo-Soikkeli M, Siurala M, Airaksinen AJ, Vähä-Koskela M and Hemminki A: Adenovirus improves the efficacy of adoptive T-cell therapy by recruiting immune cells to and promoting their activity at the tumor. Cancer Immunol Res 3 : 915-925, 2015.

22. Cavalcanti A, Santos R, Mesquita Z, Duarte AL and Lucena-Silva N: Cytokine profile in childhood-onset systemic lupus erythematosus: A cross-sectional and longitudinal study. Braz J Med Biol Res 50: e5738, 2017.

23. Yan Y, Li S, Jia T, Du X, Xu Y, Zhao Y, Li L, Liang K, Liang W, Sun H and Li R: Combined therapy with CTL cells and oncolytic adenovirus expressing IL-15-induced enhanced antitumor activity. Tumour Biol 36: 4535-4543, 2015.

24. Ray A, Das DS, Song Y, Richardson P, Munshi NC, Chauhan D and Anderson KC: Targeting PD1-PDL1 immune checkpoint in plasmacytoid dendritic cell interactions with T cells, natural killer cells and multiple myeloma cells. Leukemia 29: 1441-1444, 2015.

25. Yang J, Riella LV, Chock S, Liu T, Zhao X, Yuan X, Paterson AM, Watanabe T, Vanguri V, Yagita $\mathrm{H}$, et al: The novel costimulatory programmed death ligand 1/B7.1 pathway is functional in inhibiting alloimmune responses in vivo. J Immunol 187: 1113-1119, 2011.

26. Curiel TJ, Wei S, Dong HD, Alvarez X, Cheng P, Mottram P, Krzysiek R, Knutson KL, Daniel B, Zimmermann MC, et al: Blockade of B7-H1 improves myeloid dendritic cell-mediated antitumor immunity. Nat Med 9: 562-567, 2003.

27. Ueno H, Schmitt N, Klechevsky E, Pedroza-Gonzalez A, Matsui T, Zurawski G, Oh S, Fay J, Pascual V, Banchereau J and Palucka K: Harnessing human dendritic cell subsets for medicine. Immunol Rev 234: 199-212, 2010.

28. Volovitz I, Melzer S, Amar S, Bocsi J, Bloch M, Efroni S, Ram Z and Tárnok A: Dendritic cells in the context of human tumors: Biology and experimental tools. Int Rev Immunol 35: 116-135, 2016.

29. MacDonald KP, Munster DJ, Clark GJ, Dzionek A, Schmitz J and Hart DN: Characterization of human blood dendritic cell subsets. Blood 100: 4512-4520, 2002

30. Trinchieri G: Interleukin-12 and the regulation of innate resistance and adaptive immunity. Nat Rev Immunol 3: 133-146, 2003.

31. Vogt A, Sievers E, Lukacs-Kornek V, Decker G, Raskopf E, Meumann N, Büning H, Sauerbruch T, Strassburg CP, Schmidt-Wolf IG and Gonzalez-Carmona MA: Improving immunotherapy of hepatocellular carcinoma (HCC) using dendritic cells (DC) engineered to express IL-12 in vivo. Liver Int 34: 447-461, 2014.

32. Legitimo A, Consolini R, Failli A, Orsini G and Spisni R: Dendritic cell defects in the colorectal cancer. Hum Vacc Immunother 10: 3224-3235, 2014.

33. Huang J, Tatsumi T, Pizzoferrato E, Vujanovic N and Storkus WJ: Nitric oxide sensitizes tumor cells to dendritic cell-mediated apoptosis, uptake, and cross-presentation. Cancer Res 65: 8461-8470, 2005.

34. Liu S, Yu Y, Zhang M, Wang W and Cao X: The involvement of TNF-alpha-related apoptosis-inducing ligand in the enhanced cytotoxicity of IFN-beta-stimulated human dendritic cells to tumor cells. J Immunol 166: 5407-5415, 2001.

35. Blankenstein T: The role of tumor stroma in the interaction between tumor and immune system. Curr Opin Immunol 17: $180-186,2005$

36. Butler MO, Lee JS, Ansén S, Neuberg D, Hodi FS, Murray AP, Drury L, Berezovskaya A, Mulligan RC, Nadler LM and Hirano N: Long-lived antitumor CD8+ lymphocytes for adoptive therapy generated using an artificial antigen-presenting cell. Clin Cancer Res 13: 1857-1867, 2007. 